\title{
Increasing Awareness of the Roles, Knowledge, and Skills of Respiratory Therapists Through an Interprofessional Education Experience
}

\author{
John B Zamjahn PhD RRT RPFT, Ellen O Beyer DNP MBA PHCNS-BC APRN, \\ Kelly L Alig PhD LOTR, Donald E Mercante PhD, Katherine L Carter DNP PHCNS-BC, and \\ Tina P Gunaldo PhD DPT
}

\begin{abstract}
BACKGROUND: The objectives of this study were: (1) to assess the use of interprofessional education (IPE) to improve the knowledge and skill levels of nursing and occupational therapy students regarding respiratory therapy (RT) medical devices and techniques, nursing and RT students regarding safe patient transfers, and RT and occupational therapy students regarding safe handling of a patient's medical lines during transfers and (2) to promote collaborative behaviors. METHODS: A prospective mixed methods approach was used for data collection of an IPE highfidelity simulation experience involving 73 nursing, occupational therapy, and RT students at an academic medical institution. The Interprofessional Education Collaborative roles and responsibilities and interprofessional communication sub-competency guided the development of the IPE experience. RESULTS: The pre-post paired survey response rate was $82.2 \%$. Significant increases in student perception of learning differed by profession. Student evaluations of the IPE experience suggested that IPE increased students' knowledge of the procedures performed by the other represented professions and that students were more likely to collaborate with these professions in the future. CONCLUSIONS: IPE improved student knowledge in the roles and responsibilities competency domain. In particular, nursing and occupational therapy students became more aware of the knowledge and skill set of the RT profession. Key words: interprofessional education; interprofessional collaboration; high-fidelity simulation; nursing; occupational therapy; respiratory therapy; roles and responsibilities; curriculum; accreditation. [Respir Care 2018;63(5):510-518. (C) 2018 Daedalus Enterprises]
\end{abstract}

\section{Introduction}

The United States health-care delivery system and its stakeholders, including academia, are seeking to improve

Dr Zamjahn is affiliated with the Respiratory Therapy Program and Dr Alig is affiliated with the Occupational Therapy Program, School of Allied Health Professions; Drs Beyer and Carter are affiliated with the School of Nursing; Dr Mercante is affiliated with the School of Public Health; and Dr Gunaldo is affiliated with the Center for Interprofessional Education and Collaborative Practice, Louisiana State University Health Sciences Center, New Orleans, Louisiana.

Supplementary material related to this paper is available at http:// www.rcjournal.com.

This work was supported in part by 1 U54 GM104940 from the National Institute of General Medical Sciences of the National Institutes of Health, health-care outcomes. Collaborative teams are needed to address the complex needs of patients with multiple diagnoses or chronic diseases. ${ }^{1}$ Specific to respiratory therapy (RT), Amalakuhan and Adams ${ }^{2}$ discussed the importance of an interprofessional approach for the treatment and main-

\footnotetext{
which funds the Louisiana Clinical and Translational Science Center. The content is solely the responsibility of the authors and does not necessarily represent the official views of the National Institutes of Health. The authors have disclosed no conflicts of interest.

Correspondence: Tina P Gunaldo PhD DPT, Louisiana State University Health Sciences Center, Center for Interprofessional Education and Collaborative Practice, 1900 Gravier Street, 6B14, New Orleans, LA 70112. E-mail: tgunal@1suhsc.edu.
}

DOI: $10.4187 /$ respcare.05869 
tenance of health for those diagnosed with COPD. Interprofessional education (IPE) is a developing evidencebased approach commonly used in academic institutions to prepare students to work in teams with the goal of improving quality of care and health outcomes. IPE is defined as when students from two or more professions learn about, from and with each other. ${ }^{3}$

\section{See the Related Editorial on Page 637}

The National Academy of Sciences, formerly known as the Institute of Medicine, highlighted in 2000 the crisis of medical errors occurring within the health-care industry. ${ }^{4}$ They subsequently outlined 6 aims to improve health-care system outcomes in 2001. Health care must be safe, timely, equitable, effective, efficient, and patient-centered. ${ }^{1}$ Specific to health-care education, in 2003, the academy challenged the system to educate health professionals and students in teams focused on delivering patient-centered care, employing evidence-based practice, incorporating quality improvement, and maximizing the use of technology. ${ }^{5}$

The Interprofessional Education Collaborative (IPEC) is a panel of health education associations in the United States focused on the promotion of collaborative behaviors among health professionals. In 2011, IPEC identified 4 interprofessional competency domains for collaborative practice: values and ethics for interprofessional practice, roles and responsibilities, interprofessional communication, and teams and teamwork. ${ }^{6}$ The 4 competency domains and 39 respective sub-competencies guide interprofessional learning.

Over the past several years, many health profession accreditation organizations have developed new curricula standards that require IPE. The Commission on Accreditation for Respiratory Care specifically requires programs offering entry into respiratory care professional practice to incorporate IPE through standard 4.05 (http://www.coarc. com/29.html, Accessed July 5, 2017). ${ }^{7}$ The standard states, "Graduates must be able to function within inter-professional teams and communicate effectively with diverse populations. The curriculum must prepare students to work with a variety of populations including, but not limited to, individuals of various ages, abilities, and ethnicities." ${ }^{\prime \prime} \mathrm{Cur}-$ riculum content related to team delivery of effective patient-centered care necessitates students acquiring knowledge of the roles and responsibilities of other health-care professionals. ${ }^{7}$

Respiratory program directors and faculty in the United States favorably perceive interdisciplinary education and IPE. Vernon et $\mathrm{al}^{8}$ reported that faculty working within a bachelor's and master's degree program responded significantly higher on knowledge and beliefs about IPE as compared with faculty working within an associate's degree

\section{QUICK LOOK}

\section{Current knowledge}

The United States health-care delivery system, including academia, are seeking to improve health-care outcomes. Collaborative teams are needed to address the complex needs of patients with multiple diagnoses or chronic disease. Interprofessional education (IPE) is a developing evidence-based approach used to prepare students to work collaboratively in patient-centered teams. Two core competency domains for interprofessional collaborative practice are roles and responsibilities and interprofessional communication.

\section{What this paper contributes to our knowledge}

IPE improved student knowledge in the roles and responsibilities competency domain. In particular, nursing and occupational therapy students became more aware of the knowledge and skill set of the respiratory therapy profession. IPE encouraged collaborative practices that students perceived themselves using in future care of clients/patients involving the represented professions.

program. Regardless of the academic level, common barriers exist for IPE that can have an impact on attitudes for IPE inclusion. Barriers include lack of resources needed to develop educational experiences, lack of curricula scheduling flexibility, and faculty attitudes. ${ }^{8,9}$ However, there are factors that contribute to the success of interprofessional programs, including administrative support, interprofessional organization structure, committed faculty, and experienced faculty. ${ }^{10}$

Louisiana State University Health Sciences Center (New Orleans, Louisiana) established a Center for Interprofessional Education and Collaborative Practice in 2015. The center was the result of a goal set forth in the institution's quality enhancement plan for reaffirmation of accreditation. The administrative support and organizational development of a centralized office have been instrumental in the center's utilization. The IPE center supports faculty in the development, implementation, and evaluation of IPE experiences.

With the goal of expanding IPE opportunities, an existing IPE high-fidelity simulation experience established in 2014 with the occupational therapy and undergraduate nursing programs was enhanced to include the RT program. Learning outcomes associated with the experience included improved student-perceived knowledge and skill levels of medical lines and patient transfers, as well as student attitudes toward interprofessional learning. ${ }^{11}$ Faculty from all 3 programs collaborated to expand the IPE high-fidelity simulation experience to include the RT profession. Two 
IPE student learning objectives for the high-fidelity simulation activity included IPEC sub-competencies: (1) recognize one's limitations in skills, knowledge, and abilities (roles and responsibilities [RR2]) and (2) communicate information with health team members in a form that is understandable, avoiding discipline-specific terminology when possible (interprofessional communication [CC2]).

\section{Methods}

Faculty posted on the university's electronic educational platform 3 paper-based patient scenarios, discipline-specific evidence-based training materials, and an interprofessional session document. The interprofessional session document outlined the IPE learning objectives, timeline for the IPE experience, stimulus questions targeting the IPEC sub-competencies, and assigned student groups (see online supplementary material at http://www.rcjournal. com). Students were instructed to review all posted items, which were made available 1 week before the IPE experience. Each patient scenario included equipment frequently utilized by each profession and the need to address patient mobility. The patient needs for each case were complex, requiring involvement of all professions. The patient scenarios also delineated the discipline-specific student teaching responsibilities. The students assumed the role of the patient.

The evidence-based training materials included RT education on how to use a pressurized metered-dose inhaler (pMDI) with and without a valved holding chamber or spacer, splinted cough and huff cough techniques, troubleshooting and safe use of oxygen by way of nasal cannula, calculating oxygen size E cylinder tank duration, and principles of pulse oximetry. Additional training documents included education on common medical lines and devices used in nursing patient care, safe and proper techniques for patient transfers, and equipment commonly used in occupational therapy to increase patient independence with activities of daily living.

\section{Participants}

A total of 73 students engaged in the IPE experience. The main characteristics of student participants are re-

Table 1. Participant Characteristics

\begin{tabular}{lccc}
\hline \hline Program of Study & OT & Nursing & RT \\
\hline Participants, $n$ & 35 & 21 & 17 \\
Degree level & Master's & Bachelor's & Bachelor's \\
Curriculum, months & 27 & 34 & 24 \\
Current year of study & 2 nd & 3 rd & 1st $(n=8) ; 2$ nd $(n=9)$ \\
& & & \\
OT = occupational therapy & & & \\
RT = respiratory therapy & & & \\
\hline
\end{tabular}

ported in Table 1. All students had previously completed their program's curriculum related to the discipline-specific student teaching responsibilities of the IPE activity. These curricula included objective measures of knowledge and skills. Students were divided into 10 groups, each consisting of 1-2 RT students, 2-3 nursing students, and 3-4 occupational therapy students.

\section{Study Design}

Students were instructed to meet in a classroom before the IPE experience for a brief orientation of the timeline and to complete a pre-survey. Students were required to have an electronic device, such as a laptop or telephone, to access the pre-survey. The 44-question pre-survey included 5 demographic questions, 33 knowledge-based questions written specific to each profession that included all of the components addressed in the competencies, and 6 questions related to IPE learning experiences and IPEC student learning objectives (RR2 and CC2). The IPEC questionnaire items were developed by directly converting IPEC domain sub-competencies (RR2 and CC2) into questionnaire items and giving them a stem, either "I" or "I am able to."

After completion of the pre-survey, students participated in 3 high-fidelity simulated patient cases in a laboratory space equipped with hospital beds and various pieces of medical equipment. After all students rotated through the 3 cases, they met in a classroom for a debriefing session. Students remained in the classroom after the debriefing session to complete a 44-question post-survey using an electronic device of their choice. The post-survey included 39 questions from the pre-survey, 3 questions related to evaluation of the IPE activity, and 2 additional open-ended questions, one related to student learning and the second asking for suggestions for improvement.

The IPE experience was $95 \mathrm{~min}$ in length ( $75 \mathrm{~min}$ for the high-fidelity simulation and $20 \mathrm{~min}$ for the debriefing session). The students were given $10 \mathrm{~min}$ to complete the pre-survey and $10 \mathrm{~min}$ to complete the post-survey. Faculty facilitators were available in the simulation laboratory and classrooms throughout the entire IPE session. Students were asked to participate in the research survey portion of this study, and consent was implied by completing the preand post-survey. Survey responses were anonymous, and the study was approved by the institutional review board at the Louisiana State University Health Sciences Center (approval 8511).

\section{Data Collection and Analysis}

Students were asked to rate their knowledge and skill level related to learning objectives both pre- and postsimulation. Participants were assessed on perception of 
knowledge of nursing, RT, and occupational therapy medical equipment and its significance in patient care using a 3 -point Likert scale $(1=$ not heard of the term; $3=$ heard of the term and aware of its use/significance in patient care). Students were assessed on perception of knowledge and skill level associated with performing correct and safe patient transfers, patient instruction on use of RT devices and techniques, and identifying safety issues with nursing, RT, and occupational therapy devices, using a 4-point Likert scale $(1=$ unable to perform the task; $4=$ able to proficiently perform the task). The students indicated whether they were able to correctly use and interpret the readings from a pulse oximeter $(0=$ no; $1=$ yes $)$. A 5-point Likert scale $(1=$ strongly disagree; $5=$ strongly agree) was used to measure the responses from the 2 IPEC sub-competencies and 3 IPE activity evaluation questions. The Likert scale pre- and post-survey questionnaire items and the respective discipline responsible for instruction may be found in the supplementary material (see the online supplementary table at http://www.rcjournal.com). Two open-ended questions ("Explain how this IPE simulation experience was or was not meaningful to your learning?" and "Do you have any suggestions for improving this experience?") were included on the post-survey. All quantitative analyses were performed using the Statistical Analysis System (version 9.4). The pre/post paired comparisons were carried out using the Wilcoxon signed-rank test. All tests were 2-tailed using an $\alpha$ level of 0.05 .

\section{Results}

Overall, of the 73 possible student respondents, 70 (95.9\%) completed the pre-survey, and 67 (91.8\%) completed the post-survey. A total of $60(82.2 \%)$ pre-post paired data sets were analyzed. Participants included 6 males and 53 females, with one student preferring not to answer the gender identity question. Of these 60 participants, 50\% reported that this was their first IPE classroom experience.

Table 2 presents changes in RT students' learning perceptions of nursing and occupational therapy competencies as surveyed before and after the IPE experience. RT students demonstrated a significant increase in their perception of learning for 15 (78.9\%) of the 19 nursing and occupational therapy-focused knowledge-based questions. Exceptions were questions related to knowledge of the use and significance of a Foley catheter, percutaneous endoscopic gastrostomy feeding tube, peripherally inserted central line catheter, and transfer board in patient care.

Table 3 presents changes in nursing and occupational therapy students' learning perceptions of RT competencies as surveyed before and after the IPE experience. Nursing students demonstrated a significant increase in their perception of learning for 7 (63.6\%) of the 11 RT-focused knowledge-based questions. Exceptions were questions related to knowledge of the use and significance of a pMDI, nasal cannula, and pulse oximetry in patient care. Occupational therapy students demonstrated a significant increase in their perception of learning for all RT-focused questions.

Table 4 provides a summary of the IPEC sub-competencies across student groups as surveyed before and after the IPE experience. All student groups reported significant improvement in their ability to communicate information with health team members in a form that is understandable, avoiding discipline-specific terminology when possible. Both nursing and occupational therapy student groups showed significant improvement in recognizing their limitations in skills, knowledge, and abilities regarding patient transfers. The nursing group showed significant improvement in recognizing their limitations in skills, knowledge, and abilities regarding respiratory devices, and both nursing and RT student groups showed significant improvement in recognizing their limitations in skills, knowledge, and abilities regarding medical lines.

Overall, 67 (91.8\%) of 73 potential student respondents evaluated the IPE experience (Table 5). Approximately $98 \%$ of students surveyed agreed or strongly agreed that this IPE experience increased their knowledge of the procedures performed by a nurse, respiratory therapist, and/or an occupational therapist, and $97 \%$ of students surveyed agreed or strongly agreed that they are more likely to collaborate with one of the other professions. The vast majority $(86.6 \%)$ of students agreed or strongly agreed that the IPE experience provided sufficient time to learn from, about, and with other students, whereas $6 \%$ of students disagreed.

A total of 31 students (42.5\%) answered the open-ended question, "Explain how this IPE simulation experience was or was not meaningful to your learning." All of these students reported that the IPE simulation was a meaningful, positive experience. Participants reported their appreciation for the hands-on experience, the opportunity to work with students from each program, and increased comfort in collaborating and communicating with other healthcare professionals. In addition, students conveyed the value of experiencing how each discipline contributed to the holistic treatment of patients.

When asked for suggestions in improving the IPE experience, most participants who answered reported either needing extra time or requested the times spent in the scenarios be made more efficient. Several students commented that the first scenario seemed to take longer, which resulted in having less time to effectively complete the other 2 cases. Other suggestions included adding a scenario with an actual patient, adding students from other programs, and completing the experience earlier in the 
Table 2. Assessment of Learning Perceptions Related to Nursing and Occupational Therapy Competencies Across the Respiratory Therapy Student Group

\begin{tabular}{|c|c|c|c|}
\hline Questionnaire Items & $\begin{array}{l}\text { Pre-Survey RT } \\
\text { Students }(n=13)\end{array}$ & $\begin{array}{l}\text { Post-Survey RT } \\
\text { Students }(n=13)\end{array}$ & $P$ \\
\hline \multicolumn{4}{|l|}{ I have heard of the term and aware of its use/significance in patient care* } \\
\hline \multicolumn{4}{|l|}{ Nursing focus } \\
\hline Foley catheter & $2.76 \pm 0.43$ & $3.00 \pm 0.00$ & .25 \\
\hline Jackson-Pratt drain & $1.61 \pm 0.65$ & $3.00 \pm 0.00$ & $<.001$ \\
\hline PEG feeding tube & $2.69 \pm 0.48$ & $2.84 \pm 0.37$ & .62 \\
\hline PICC & $2.58 \pm 0.51$ & $2.84 \pm 0.37$ & .37 \\
\hline \multicolumn{4}{|l|}{ Occupational therapy focus } \\
\hline Stand-pivot transfer & $2.23 \pm 0.72$ & $2.92 \pm 0.27$ & .007 \\
\hline Transfer board & $2.46 \pm 0.77$ & $3.00 \pm 0.00$ & .062 \\
\hline \multicolumn{4}{|l|}{ I am able to correctly and safely assist a patient with the following } \\
\hline \multicolumn{4}{|l|}{ Occupational therapy focus } \\
\hline Rolling in bed & $2.76 \pm 0.59$ & $3.84 \pm 0.37$ & .001 \\
\hline Transferring from supine to sitting on the edge of the bed & $2.84 \pm 0.80$ & $3.84 \pm 0.37$ & .01 \\
\hline $\begin{array}{l}\text { Transferring from sitting on the edge of the bed to standing by } \\
\text { the side of the bed }\end{array}$ & $2.76 \pm 0.59$ & $3.76 \pm 0.43$ & .001 \\
\hline $\begin{array}{l}\text { Transferring from sitting on the edge of the bed to a chair using } \\
\text { a transfer board }\end{array}$ & $2.76 \pm 0.59$ & $3.61 \pm 0.50$ & .007 \\
\hline $\begin{array}{l}\text { Transferring from sitting on the edge of the bed to a chair using } \\
\text { a stand pivot transfer }\end{array}$ & $2.69 \pm 0.63$ & $3.69 \pm 0.48$ & .001 \\
\hline \multicolumn{4}{|l|}{$\begin{array}{l}\text { I am able to correctly and safely assist a patient move around in bed or in } \\
\text { a hospital room if he/she has the following device }\end{array}$} \\
\hline \multicolumn{4}{|l|}{ Nursing and occupational therapy focus } \\
\hline Foley catheter & $2.07 \pm 0.75$ & $3.23 \pm 0.72$ & $<.001$ \\
\hline Jackson-Pratt drain & $1.46 \pm 0.66$ & $3.23 \pm 0.72$ & $<.001$ \\
\hline PEG feeding tube & $2.15 \pm 0.89$ & $3.07 \pm 0.75$ & .02 \\
\hline PICC & $2.07 \pm 0.95$ & $3.00 \pm 0.81$ & .01 \\
\hline \multicolumn{4}{|l|}{ I am able to identify issues with the following devices } \\
\hline \multicolumn{4}{|l|}{ Nursing focus } \\
\hline PEG feeding tube & $1.84 \pm 0.68$ & $3.07 \pm 0.86$ & .003 \\
\hline Foley catheter & $1.69 \pm 0.85$ & $3.07 \pm 0.86$ & $<.001$ \\
\hline Jackson-Pratt drain & $1.41 \pm 0.66$ & $3.00 \pm 0.81$ & .001 \\
\hline PICC & $1.84 \pm 0.98$ & $3.07 \pm 0.86$ & .001 \\
\hline $\begin{array}{l}\text { Results are mean } \pm \mathrm{S} D \text {. Unless otherwise indicated }(*) \text {, all questionnaire items used a 4-point } \\
\text { needed to perform the task, but require further instructions; } 3=\mathrm{I} \text { am able to perform the task; } \\
* \text { Likert scale }(1=\mathrm{I} \text { have not heard of the term; } 2=\mathrm{I} \text { have heard of the term but am unaware } \\
\text { use/significance in patient care). } \\
\text { RT }=\text { respiratory therapy } \\
\text { PEG = percutaneous endoscopic gastrostomy } \\
\text { PICC = peripherally inserted central line catheter }\end{array}$ & $\begin{array}{l}\text { I am unable to perform the } \\
\text { proficiently perform the ta } \\
\text { cance in patient care; } 3=\text { I }\end{array}$ & $\begin{array}{l}\text { time; } 2=\mathrm{I} \text { have the knov } \\
\text { of the term and am aware }\end{array}$ & skills \\
\hline
\end{tabular}

curriculum. One respondent recommended that each discipline have the opportunity to explain equipment or procedures first, outside of the context of the scenarios.

\section{Discussion}

Our IPE high-fidelity simulation experience allowed for nursing, RT, and occupational therapy students to work collaboratively as interprofessional patient-centered teams to learn about, from, and with each other, acquiring knowledge of each other's roles and responsibilities as healthcare professionals. IPEC provided a general competency statement for the roles and responsibilities domain, which includes using knowledge about one's roles and other professional roles when providing health care. Over $98 \%$ of students agreed or strongly agreed that the IPE experience increased their knowledge of the procedures performed by a respiratory therapist, nurse, and/or an occupational therapist, and $97 \%$ of students agreed or strongly agreed that they are more likely to collaborate with one of the other professions (Table 5). The results from this study are promising, as students who are trained in an interprofessional manner are more likely to form collaborative practice patterns after graduation. ${ }^{12}$ 
Table 3. Assessment of Learning Perceptions Related to Respiratory Therapy Competencies Across Nursing and Occupational Therapy Student Groups

\begin{tabular}{|c|c|c|c|c|c|c|}
\hline Questionnaire Items & $\begin{array}{c}\text { Pre-Survey } \\
\text { Nursing Students } \\
(n=21)\end{array}$ & $\begin{array}{c}\text { Post-Survey } \\
\text { Nursing Students } \\
(n=21)\end{array}$ & $P$ & $\begin{array}{l}\text { Pre-Survey } \\
\text { OT Students } \\
(n=26)\end{array}$ & $\begin{array}{l}\text { Post-Survey } \\
\text { OT Students } \\
\quad(n=26)\end{array}$ & $P$ \\
\hline \multicolumn{7}{|l|}{$\begin{array}{l}\text { I have heard of the term and am aware of its } \\
\text { use/significance in patient care* }\end{array}$} \\
\hline pMDI & $2.90 \pm 0.30$ & $3.00 \pm 0.00$ & .50 & $1.53 \pm 0.70$ & $2.88 \pm 0.43$ & $<.001$ \\
\hline Nasal cannula & $3.00 \pm 0.00$ & $3.00 \pm 0.00$ & $>.99$ & $2.30 \pm 0.73$ & $2.96 \pm 0.19$ & $<.001$ \\
\hline Pulse oximetry & $3.00 \pm 0.00$ & $3.00 \pm 0.00$ & $>.99$ & $2.65 \pm 0.56$ & $2.96 \pm 0.19$ & .01 \\
\hline \multicolumn{7}{|c|}{$\begin{array}{l}\text { I am able to correctly and safely assist a patient move } \\
\text { around in bed or in a hospital room if he/she has the } \\
\text { following device }\end{array}$} \\
\hline Nasal cannula & $3.57 \pm 0.50$ & $3.85 \pm 0.35$ & .031 & $1.72 \pm 0.93 \dagger$ & $3.30 \pm 0.78 \dagger$ & $<.001$ \\
\hline \multicolumn{7}{|l|}{$\begin{array}{l}\text { I am able to correctly and safely instruct a patient on } \\
\text { the following }\end{array}$} \\
\hline Huff cough & $1.85 \pm 0.85$ & $3.61 \pm 0.58$ & $<.001$ & $1.07 \pm 0.39$ & $2.96 \pm 0.72$ & $<.001$ \\
\hline pMDI with a spacer & $2.52 \pm 0.87$ & $3.61 \pm 0.49$ & $<.001$ & $1.19 \pm 0.49$ & $3.11 \pm 0.76$ & $<.001$ \\
\hline pMDI without a spacer & $2.42 \pm 0.81$ & $3.61 \pm 0.49$ & $<.001$ & $1.15 \pm 0.46$ & $3.11 \pm 0.71$ & $<.001$ \\
\hline Splinted cough & $2.76 \pm 0.94$ & $3.76 \pm 0.43$ & $<.001$ & $1.00 \pm 0.00$ & $3.00 \pm 0.84$ & $<.001$ \\
\hline Safety issues regarding use of oxygen therapy & $2.71 \pm 0.78$ & $3.85 \pm 0.35$ & $<.001$ & $1.34 \pm 0.56$ & $2.88 \pm 0.76$ & $<.001$ \\
\hline \multicolumn{7}{|l|}{ I am able to identify issues with the following devices } \\
\hline Nasal cannula & $3.47 \pm 0.60$ & $3.90 \pm 0.30$ & .003 & $1.23 \pm 0.58$ & $3.11 \pm 0.71$ & $<.001$ \\
\hline Pulse oximeter $\ddagger$ & $1.00 \pm 0.00$ & $1.00 \pm 0.00$ & $>.99$ & $0.53 \pm 0.50$ & $0.92 \pm 0.27$ & .001 \\
\hline \multicolumn{7}{|c|}{$\begin{array}{l}\text { Results are mean } \pm \text { SD. Unless otherwise indicated }(* \text { and } \ddagger) \text {, all questionnaire items use a 4-point Likert scale }(1=\mathrm{I} \text { am unable to perform the task at this time; } 2=\mathrm{I} \text { have the knowledge and skills } \\
\text { needed to perform the task, but require further instructions; } 3=\mathrm{I} \text { am able to perform the task; } 4=\mathrm{I} \text { am able to proficiently perform the task). } \\
* \text { Likert scale }(1=\mathrm{I} \text { have not heard of the term; } 2=\mathrm{I} \text { have heard of the term but am unaware of its use/significance in patient care; } 3=\mathrm{I} \text { have heard of the term and am aware of its } \\
\text { use/significance in patient care). } \\
\dagger n=25 \text {. } \\
\ddagger \text { Likert scale }(0=\text { no; } 1=\text { yes). } \\
\text { OT }=\text { occupational therapy } \\
\text { pMDI = pressurized metered-dose inhaler }\end{array}$} \\
\hline
\end{tabular}

Given the caveat of different means of assessment, several IPE studies ${ }^{13-16}$ involving RT student participants have reported improvements in participant knowledge of roles and responsibilities or role clarity. However, these studies did not specifically provide learning outcomes by various student groups. So it is unknown whether RT students perceived greater learning in the roles and responsibilities domain as compared with other students representing different professions or vice versa. Data in Table 2 indicate that RT students participating in this IPE experience did not demonstrate a significant increase in their perception of learning, from pre- to post-IPE experience, related to knowledge of the Foley catheter, percutaneous endoscopic gastrostomy tube, peripherally inserted central line catheter line, and transfer board. The pre-survey means for these questions were high, 2.76, 2.69, 2.58, and 2.46, respectively, on a 3-point Likert scale, indicating that most RT students were aware of the use of the 3 medical lines and transfer board in patient care. However, RT students indicated improved learning with the Foley catheter, percutaneous endoscopic gastrostomy feeding tube, peripherally inserted central line catheter line, and transfer board as it related to identifying issues with the medical line or equipment and safe patient transfers.

The RT students' initial perception of their limitations in skills, knowledge, and abilities regarding patient transfers was similar after the IPE experience (Table 4). The pre-survey mean was 4.07 on a 5 -point Likert scale. The pre-mean score could have been influenced by having both first and second year level RT students engaged in the experience or the fact that RT students are provided education regarding the use of proper body mechanics during occupational duties during their first semester enrolled in the program.

Changes in nursing and occupational therapy students' perceived knowledge of RT medical devices and their use/significance in patient care differed. The occupational therapy students, but not the nursing students, demonstrated significant improvement in their perception of knowledge of a pMDI, nasal cannula, or pulse oximetry and their use/significance in patient care (Table 3 ). The nursing pre-survey means for these questions were 2.90, 3.00, and 3.00, respectively, on a 3-point Likert scale, indicating that most, if not all, nursing students were aware 
Interprofessional Educational Experience for Health Professionals

Table 4. Assessment of Interprofessional Education Collaborative Sub-Competencies Across Student Groups

\begin{tabular}{|c|c|c|c|}
\hline $\begin{array}{l}\text { IPEC Sub-Competency Questionnaire Items } \\
\text { and Student Group }\end{array}$ & Pre-Survey & Post-Survey & $P$ \\
\hline \multicolumn{4}{|l|}{$\begin{array}{l}\text { I am able to communicate information with health team } \\
\text { members in a form that is understandable, avoiding } \\
\text { discipline-specific terminology when possible }\end{array}$} \\
\hline All & $4.03 \pm 0.51$ & $4.58 \pm 0.53$ & $<.001$ \\
\hline Nursing & $4.14 \pm 0.57$ & $4.61 \pm 0.49$ & .006 \\
\hline OT & $3.96 \pm 0.44$ & $4.61 \pm 0.49$ & $<.001$ \\
\hline $\mathrm{RT}$ & $4.00 \pm 0.57$ & $4.46 \pm 0.66$ & .031 \\
\hline \multicolumn{4}{|l|}{$\begin{array}{l}\text { I recognize my limitations in skills, knowledge, and } \\
\text { abilities regarding patient transfers }\end{array}$} \\
\hline All & $4.01 \pm 0.65$ & $4.40 \pm 0.66$ & $<.001$ \\
\hline Nursing & $4.09 \pm 0.70$ & $4.42 \pm 0.74$ & .01 \\
\hline OT & $3.92 \pm 0.62$ & $4.38 \pm 0.63$ & .003 \\
\hline $\mathrm{RT}$ & $4.07 \pm 0.64$ & $4.38 \pm 0.65$ & .12 \\
\hline \multicolumn{4}{|l|}{$\begin{array}{l}\text { I recognize my limitations in skills, knowledge, and } \\
\text { abilities regarding respiratory devices }\end{array}$} \\
\hline All & $4.15 \pm 0.77$ & $4.35 \pm 0.63$ & .01 \\
\hline Nursing & $4.04 \pm 0.74$ & $4.38 \pm 0.74$ & .01 \\
\hline OT & $4.19 \pm 0.80$ & $4.34 \pm 0.48$ & .36 \\
\hline $\mathrm{RT}$ & $4.23 \pm 0.83$ & $4.30 \pm 0.75$ & $>.99$ \\
\hline \multicolumn{4}{|l|}{$\begin{array}{l}\text { I recognize my limitations in skills, knowledge, and } \\
\text { abilities regarding medical lines }\end{array}$} \\
\hline All & $4.06 \pm 0.73$ & $4.40 \pm 0.64$ & $<.001$ \\
\hline Nursing & $3.95 \pm 0.86$ & $4.42 \pm 0.81$ & .003 \\
\hline OT & $4.19 \pm 0.69$ & $4.34 \pm 0.48$ & .43 \\
\hline $\mathrm{RT}$ & $4.00 \pm 0.57$ & $4.46 \pm 0.66$ & .031 \\
\hline \multicolumn{4}{|c|}{$\begin{array}{l}\text { Results are mean } \pm \text { SD. For the all student group, } n=60 \text {; for the nursing student group, } n=21 \text {; for the respiratory therapy student group, } n=13 \text {; and for the occupational therapy student group, } \\
n=26 \text {. All questionnaire items used a } 5 \text {-point Likert scale }(1=\text { strongly disagree; } 2=\text { disagree; } 3=\text { neutral; } 4=\text { agree; } 5=\text { strongly agree). } \\
\text { IPEC = Interprofessional Education Collaborative } \\
\text { OT = occupational therapy } \\
\text { RT = respiratory therapy }\end{array}$} \\
\hline
\end{tabular}

Table 5. Student Evaluation of Interprofessional Education Activity

\begin{tabular}{|c|c|c|c|c|c|}
\hline Questionnaire Item & Strongly Disagree & Disagree & Neutral & Agree & Strongly Agree \\
\hline $\begin{array}{l}\text { This IPE experience increased my knowledge of } \\
\text { the procedures performed by a nurse, } \\
\text { respiratory therapist, and/or an occupational } \\
\text { therapist }\end{array}$ & $0(0)$ & $0(0)$ & $1(1.5)$ & $32(47.8)$ & $34(50.7)$ \\
\hline $\begin{array}{l}\text { This IPE experience provided sufficient time to } \\
\text { learn from, about, and with other students }\end{array}$ & $0(0)$ & $4(6.0)$ & $5(7.5)$ & $26(38.8)$ & $32(47.8)$ \\
\hline $\begin{array}{l}\text { Because of this IPE experience, I will be more } \\
\text { likely to collaborate with one of the } \\
\text { professions represented today }\end{array}$ & $0(0)$ & $0(0)$ & $2(3.0)$ & $30(44.8)$ & $35(52.2)$ \\
\hline
\end{tabular}

of a pMDI, nasal cannula, or pulse oximetry. The nursing students were senior-level students and had been exposed to the 3 terms. In addition, before this IPE experience, as part of the existing curriculum, nursing students had discussed the use of nasal cannula and pulse oximetry with occupational therapy students.
Nursing and occupational therapy students indicated significant learning with correct and safe assistance in ambulating patients with a nasal cannula, correct and safe patient instruction on the huff and splinted cough techniques, use of a pMDI with and without a spacer, safety issues regarding use of oxygen therapy, and troubleshoot- 
ing a non-working nasal cannula (Table 3). Nursing but not occupational therapy students' perception of their limitations in skills, knowledge, and abilities regarding respiratory devices was increased after the IPE experience (Table 4). The occupational therapy pre-survey mean for the IPEC sub-competency was 4.19 on a 5-point Likert scale, indicating that occupational therapy students were aware of their limitations in skills, knowledge, and abilities regarding respiratory devices. Occupational therapy and nursing student groups had similarly high post-survey IPEC sub-competency mean scores (4.34 and 4.38, respectively).

Nursing and occupational therapy students' awareness of RT devices and techniques may allow for timely adjustment or notification of incorrect use or safety issues. Incorrect pMDI technique is frequent (up to $70-80 \%$ ) among asthma and COPD patients. ${ }^{17-19}$ Guidelines for asthma and COPD management recommend assessment of inhaler technique at every patient visit. ${ }^{19,20}$ However, studies have shown that health-care professionals (up to 69$85 \%)$ lack inhaler technique knowledge and skill..21-23 In our study, nursing and occupational therapy student groups initially indicated a need for further instruction or were unable to correctly and safely instruct a patient on the use of a pMDI. Adding a physical demonstration to educational interventions is shown to be more effective in improving pMDI technique than are written and verbal instructions alone. ${ }^{24}$ In our study, an objective assessment of students' knowledge of correct pMDI use was not done, but students did indicate a perceived improvement in their understanding of the pMDI techniques after the IPE experience.

It is promising to see an increase in nursing and occupational therapy student knowledge about the RT profession. Increased knowledge about professional roles has the potential to positively impact patient outcomes. The following example cannot be reported as a study result; however, it does provide insight to the possibility of improving health care. After the IPE session, nursing students participated in clinical rotations in home settings. While in the home of a patient, a nursing student observed that the flow meter was set at a level that required the use of a humidifier, and the nursing student recommended that a humidifier be connected. Before the IPE session, the nursing student indicated that she would have not made that observation and subsequent recommendation. In this particular case, the patient's health-care experience was improved through the result of IPE.

Limitations of the study included the students were sampled by convenience from bachelor's and master's degree programs at a single large southern academic medical center, the small number of students participating, data analysis was from a one-time experience, and there was no control group. Another limitation was the level of prepa- ration each group received from each of their respective faculty before the IPE experience. Each group received electronic educational materials, but some students received more in-depth preparation about the goals and objectives for the IPE experience.

\section{Conclusions}

IPE training within an academic environment increases student knowledge of the roles and responsibilities of other health-care providers and promotes collaborative behaviors. Further research is needed to measure post-graduation collaborative behaviors and its impact on patient health outcomes.

\section{ACKNOWLEDGMENTS}

We thank Bobby Moore MA (Education Coordinator, Center for Interprofessional Education and Collaborative Practice at Louisiana State University Health Sciences Center - New Orleans) for assisting in the development and coordination of the IPE activity.

\section{REFERENCES}

1. Institute of Medicine. Crossing the quality chasm: a new health system for the 21st century. Washington, DC: The National Academies Press; 2001:211.

2. Amalakuhan B, Adams SG. Improving outcomes in chronic obstructive pulmonary disease: the role of the interprofessional approach. Int J Chron Obstruct Pulmon Dis 2015;10:1225-1232.

3. World Health Organization. Framework for action on interprofessional education and collaborative practice. Geneva: World Health Organization; 2010. http://www.who.int/hrh/resources/framework_ action/en/. Accessed May 9, 2016.

4. Institute of Medicine. To err is human: building a safer health system. Washington, DC: The National Academies Press; 2000.

5. Institute of Medicine. Health professions education: a bridge to quality. Washington, DC: The National Academies Press; 2003:23.

6. Interprofessional Education Collaborative Expert Panel. Core competencies for interprofessional collaborative practice: 2016 update. Washington, DC: Interprofessional Education Collaborative; 2016:10.

7. Commission on Accreditation for Respiratory Care. CoARC accreditation standards for entry into respiratory care professional practice; 1962, revised 2016. http://www.coarc.com/29.html. Accessed July 5, 2017.

8. Vernon MM, Moore NM, Cummins LA, Reyes SE, Mazzoli AJ, Heboyan V, De Leo G. Respiratory therapy faculty knowledge of and attitudes toward interprofessional education. Respir Care 2017; 62(7):873-881.

9. Rye KJ, Shelledy DC. Utilization of interdisciplinary education in respiratory care curricula. Respir Care Educ Annu 2011;20:1-10.

10. Bridges DR, Davidson RA, Odegard PS, Maki IV, Tomkowiak J. Interprofessional collaboration: three best practice models of interprofessional education. Med Educ Online; 2011;16: 10.3402/ meo.v16i0.6035.

11. Jacobs R, Beyer E, Carter K. Interprofessional simulation education designed to teach occupational therapy and nursing students complex patient transfers. J Interprof Educ Practice 2017;6:67-70.

12. Pecukonis E, Doyle O, Bliss D. Reducing barriers to interprofessional training: promoting interprofessional cultural competence. J Interprof Care 2008;22(4):417-428. 
13. Sigalet EL, Donnon TL, Grant V. Insight into team competence in medical, nursing and respiratory therapy students. J Interprof Care 2015; 29(1):62-67.

14. King AE, Conrad M, Ahmed RA. Improving collaboration among medical, nursing and respiratory therapy students through interprofessional simulation. J Interprof Care 2013;27(3):269-271.

15. Sergakis G, Clutter J, Holthaus V, Nahikian-Nelms M, Rohrig L, Legg $\mathrm{J}$, et al. The impact of interprofessional clinical simulation on attitudes, confidence and professional identity: the added value of integrating respiratory therapy. Respir Care Educ Annu 2016;25:11-16.

16. King J, Beanlands S, Fiset V, Chartrand L, Clarke S, Findlay T, et al. Using interprofessional simulation to improve collaborative competences for nursing, physiotherapy, and respiratory therapy students. J Interprof Care 2016;30(5):599-605.

17. Molimard M, Raherison C, Lignot S, Balestra A, Lamarque S, Chartier A, et al. Chronic obstructive pulmonary disease exacerbation and inhaler device handling: real-life assessment of 2935 patients. Eur Respir J 2017;49(2):1601794.

18. Sanchis J, Gich I, Pedersen S, Aerosol Drug Management Improvement Team (ADMIT). Systematic review of errors in inhaler use: has patient technique improved over time? Chest 2016;150(2): 394-406.

19. Global Initiative for Asthma. Global strategy for asthma management and prevention, 2017. www.ginasthma.org. Accessed October 10, 2017.

20. Global Initiative for Chronic Obstructive Lung Disease (GOLD). Global strategy for the diagnosis, management and prevention of COPD, 2017. http://goldcopd.org. Accessed October 10, 2017.

21. Alismail A, Song CA, Terry MH, Daher N, Almutairi WA, Lo T. Diverse inhaler devices: a big challenge for health-care professionals. Respir Care 2016;61(5):593-599.

22. Self TH, Arnold LB, Czosnowski LM, Swanson JM, Swanson H. Inadequate skill of healthcare professionals in using asthma inhalation devices. J Asthma 2007;44(8):593-598.

23. Inhaler Error Steering Committee, Price D, Bosnic-Anticevich S, Briggs A, Chrystyn H, Rand C, et al. Inhaler competence in asthma: common errors, barriers to use and recommended solutions. Respir Med 2013;107(1):37-46.

24. Bosnic-Anticevich SZ, Sinha H, So S, Reddel HK. Metered-dose inhaler technique: the effect of two educational interventions delivered in community pharmacy over time. J Asthma 2010;47(3):251-256.

This article is approved for Continuing Respiratory Care Education credit. For information and to obtain your CRCE

(free to AARC members) visit

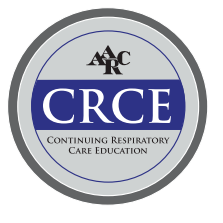

